\title{
4
}

\section{THE LONG ARC OF MOSQUITO CONTROL}

\author{
James L.A. Webb, Jr.
}

Long before the emergence of Homo sapiens, our early hominid ancestors frequently found themselves in close proximity and intimate contact with mosquitoes. Our distant ancestors sojourned nearby bodies of saltwater in order to harvest shellfish and catch marine fish as a source of protein, and by the shores of freshwater rivers, lakes and streams to catch freshwater fish, have ready access to drinking water and hunt animals that came to rehydrate themselves. Mosquitoes likewise were drawn to watery environments. Many species needed salt marshes or the edges of bodies of fresh water in which to lay their eggs, which would develop into larvae, pupae and adult mosquitoes.

In deep time, the biological destinies of human beings and mosquitoes became intertwined. The females of some mosquito species began to take blood meals from humans as well as other animals. Through these blood meals, necessary to nurture their ova, some mosquito species acquired viral and protozoal parasites, eventually evolving the capacity to host these parasites and transmit them. In early tropical Africa, where Homo sapiens spent most of its early career, the watery environments were conducive to the spread of mosquito-borne diseases such as malaria, yellow fever and lymphatic filariasis. The disease burden of malaria was so strong that it produced widespread genetic adaptations in human populations (Webb 2009).

In both saltwater and freshwater environments, mosquito populations could be exceedingly dense and constitute a nearly unbearable nuisance as well as a health burden. Our ancestors did what they could: they built smoking fires and in some world regions such as West Africa applied plant repellents to their bodies to try to keep mosquitoes at bay (Iroko 1994). These measures constituted an early chapter in the long struggle of humanity to limit our exposure to mosquitoes. They were only partially effective, however, and had little impact on the transmission of mosquito-borne disease. 


\section{Mosquitoes and ecological transformations}

During the long transition from gathering and hunting to the cultivation of foodstuffs, human beings transformed local environments to make them suitable for agriculture. In the process, we produced a wide range of unintended consequences, some of which altered our relationships with mosquitoes. In tropical Africa, for example, the clearing of West African rainforest to facilitate the spread of yam vegeculture produced environments that collected rainwater in small puddles that were conducive to mosquito breeding. Some species of Anopheles mosquitoes (the genus that can transmit malaria) bred nearby early agricultural villages and evolved to specialize in taking human blood meals, thereby intensifying the transmission of malaria (Webb 2009).

In some world regions, societies undertook large-scale environmental transformations of watery landscapes in order to make them suitable for farming or herding. One prime example is that of the North Atlantic wetlands. Since Roman times, the marshlands of Europe had repeatedly been ditched and/or diked, to drain the wetlands and/or block the inflow of saltwater (Hatvany 2003). These tactics produced varied results. In the notorious marshlands of Kent, England, the diking of the marshlands in the sixteenth century may have inadvertently improved the habitat for Anopheles atroparvus, the most important malaria mosquito vector in the British Isles, and consequently increased malaria transmission. But by the second half of the nineteenth century, the incidence of malaria in these wetlands had dropped dramatically. Marsh drainage likely played an important role, although there were other factors involved in the decline, such as improved housing with screened windows and doors and the ready availability of such medicines as quinine and other antimalarial alkaloids isolated from cinchona bark (Dobson 1980). Another contribution to the reduction in malaria transmission was the colonization of the British marshlands, beginning in 1870, by a hybrid species of marsh grass, Spartina townsendii. This plant spread throughout the marshlands of the British Isles and along the coasts of Atlantic Europe, stabilizing silt and elevating the wetlands, making them suitable for "reclamation," which generally meant ways to make grasslands available to grazing livestock (Ranwell 1967). Endemic malaria in England was eliminated by the end of the nineteenth century (Dobson 1980).

Vigorous programmes of wetland management and mosquito reduction likewise developed on the other side of the North Atlantic, when European migrants transferred their knowledge of marshland utilization to North America. Some burgeoning seaports saw nearby salt marshes filled in for industrial and urban growth projects. In the area around Boston after the late eighteenth century, for example, some $81 \%$ of marshes were converted to other uses (Seasholes 2018). In the agricultural regions of the northeastern seaboard of the United States, farmers drained salt marshes in order to boost yields of coastal marsh grasses for animal bedding, feed, and roof thatching, and in the process significantly reduced mosquito densities which in turn made work on former wetlands more feasible. In the second half of the nineteenth century, some farmers installed tidal gates to 
drain salt marshes for converting them to freshwater crops (Bourn and Cottam 1950, Crain et al. 2009).

During the economic depression of the 1930s, US governmental programmes such as the Civilian Conservation Corps and the Works Progress Administration offered employment in draining coastal wetlands in the eastern and southern states. Over all, more than $90 \%$ of the saltwater marshes between Virginia and Maine had ditches dug into them. The marsh draining work reached all the way down the eastern seaboard to Florida and around the Gulf of Mexico as far as Texas (Patterson 1998, 2009). Such ditch-digging programmes had a dual purpose. Their primary goal, pursued long before the Great Depression, had been to reduce the density of Aedes sollicitans and Aedes taeniorhynchus, saltwater mosquitoes targeted principally because their aggressive biting habits rendered much of the coastal seaboard uninhabitable; it should be noted that these Aedes mosquitoes could also transmit viral pathogens that caused Eastern equine encephalitis and Venezuelan equine encephalitis, even if such infections were generally low, going typically undiagnosed. The secondary goal of drainage programmes was to control malaria (Daiber 1986), although most malaria transmission occurred in ecological zones that were not coastal.

\section{Malaria and yellow fever mosquito control}

Since its introduction in the seventeenth century, the principal mosquito-borne disease threat to human beings in the Northwestern Atlantic had been malaria. In this temperate region, transmission of malaria occurred during the summer months. The shores of New England lakes were prime breeding grounds for the Anopheles quadrimaculatus mosquito, a competent malaria vector that fanned outbreaks of disease when warm weather brought vacationers and locals to the lakes for recreation (Holmes 1838). Protected riverbanks and eddies also provided good mosquito habitat, and in Canada, particularly in southern Ontario and Toronto, malaria was also a seasonal scourge.

In the late nineteenth and early twentieth centuries, key scientific discoveries revealed the role of mosquitoes in transmitting malaria and yellow fever. In 1880, Alphonse Laveran identified malaria plasmodia in the infected blood of malaria sufferers in Algeria. In 1897, Ronald Ross in British India demonstrated that the anopheline species was the vector for bird malaria, and in 1898, Giovanni Grassi and his Italian colleagues found that other anopheline species were the vectors that transmitted human malaria, and they described the life cycle of the falciparum malaria parasite. In 1900, Walter Reed of the US Army medical corps in Cuba confirmed the hypothesis of Carlos Finlay that mosquitoes transmit the yellow fever virus, and that Aedes aegypti mosquito is its regional vector in the Americas (Harrison 1978).

Armed with these new understandings, public health scientists focused their efforts to control malaria and yellow fever on the destruction of mosquito habitat. The fact that malaria was a globally distributed disease meant that there was a large variety of anopheline mosquitoes able to transmit the disease, albeit 
with a broad range of competency in so doing. Malarial vector species bred in a variety of habitats and relied on various feeding behaviours. The formidable challenges in understanding such vectors helped create the discipline of "tropical medicine." Although malaria existed in wealthier nations of the Global North, including northern regions such as Sweden and Canada, the principal burden of this disease was borne by populations throughout the tropics. In part, this was because the malaria parasites common in the Global North, Plasmodium vivax and Plasmodium malariae, were less lethal than Plasmodium falciparum, common in the Global South, and because the mosquito vectors in the Global North were not as competent in transmitting in the parasites. Similarly, the principal burden of yellow fever was concentrated in tropical regions, although some European and North American cities in the eighteenth to early twentieth centuries also suffered the scourge of yellow plague (Coleman 1987, McNeill 2010). Other widespread mosquito-borne diseases, such as dengue fever and chikungunya fever, were also principally transmitted in the tropics, although they were not scientifically identified until the mid-twentieth century.

The nature of the efforts to control vectors of yellow fever and malaria differed, because their breeding habitats differed. Aedes aegypti was a domestic mosquito, which meant that it bred principally in anthropogenically altered environments, often in or near human dwellings. By contrast, the array of malaria mosquito vectors was typically not domestic. They bred in marshes, river eddies, lake and pond edges, tree stumps and even small depressions from footprints which collected rainwater. The struggle against yellow fever involved military or quasi-military programmes, mandating city and town dwellers to destroy mosquito habitat in their immediate surroundings, or else harnessing military forces to carry out these functions within domestic spaces. In early-twentiethcentury Havana, for example, the US military carried out a programme of urban "sanitation" that involved fumigating the city centre, together with the oiling or removal of water-collecting vessels with open lids. In Brazil in the 1930s, the public health department, under the leadership of Fred Soper, organized a quasimilitary strategy of regularly inspecting domestic spaces to ensure compliance with the orders to eliminate Aedes aegypti breeding sites (Stepan 2011).

In the early twentieth century, disease control programmes that targeted malaria-carrying mosquitoes were carried out in many tropical and subtropical regions (Watson 1921, Harrison 1978, Farley 2003). They were most successful when focused on identifying local malarial vectors and on detailed knowledge of their spatial distribution and bionomics, which included their breeding habitats, feeding habits and flight ranges. This focused approach to local epidemiological intervention was known as species sanitation. It was pioneered by Malcolm Watson in the Federated Malay States during the early years of the twentieth century (Watson 1921). During a visit to the Dutch East Indies, Watson taught the basics of the local epidemiological approach using anopheline bionomics to the Dutch scientist Nicolaas H. Swellengrebel, who would use this method to transform anopheline breeding grounds in both the Dutch East Indies and the 
Netherlands themselves (Verhave 2011). This method was also taken up with success by the French in Algeria, shortly after the conclusion of the First World War (Sergent and Sergent 1947). Later in his career, Watson brought the techniques of species sanitation to the copper-mining zone in central Africa (Watson 1953). In the southern United States, beginning in the 1930s, the construction of hydro-electric dams had a major impact on local densities of both nuisance and malaria-vector mosquitoes, when authorities carried out control measures such as oiling and brush removal (United States Public Health Service and Tennessee Valley Authority 1947).

Species sanitation was not the only approach to malaria control. Some early malaria specialists took the view that the best approach to controlling malaria was to raise the socio-economic status of the afflicted populations, with the antimalarial drug quinine being useful in restoring the health and maintaining the economic productivity of those stricken by malaria (Verhave 2011). The Italians,

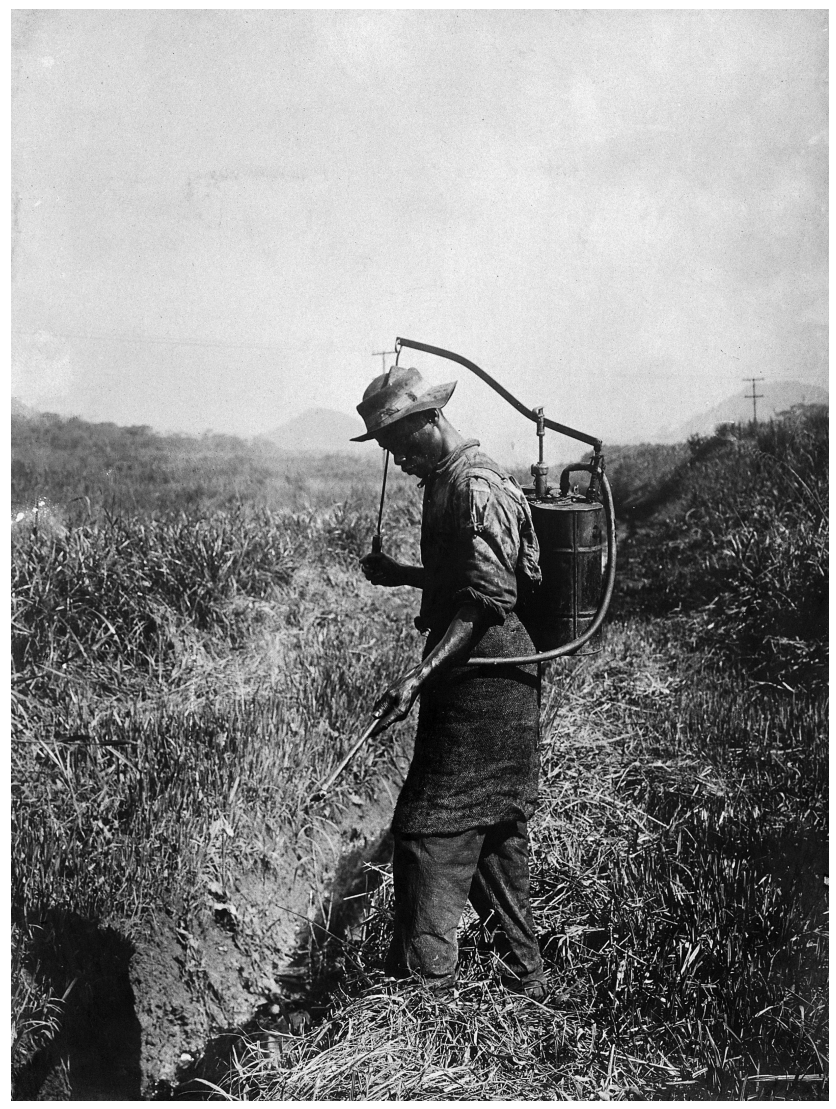

FIGURE 4.1 Miraflores, the Panama Canal Zone: a West Indian man sprays larvicide into a ditch as part of a mosquito control programme implemented during the construction of the Panama Canal. Photograph, 1910. 
beginning in 1904, undertook a nationwide campaign to provide quinine to the entire population in order to cure and protect by prophylaxis (Snowden 2006). This was broadly successful in reducing mortality, but was less so in reducing morbidity. Yet even in Italy, by the 1920s, there was a programmatic turn towards mosquito control, with a major focus on the draining of the notoriously unhealthy Pontine marshes near Rome. With assistance from the Rockefeller Foundation, the Italians undertook a marshland drainage programme complemented by the application of Paris Green, an arsenic-based insecticide that killed the anopheline mosquito larvae in the newly dug drainage canals (Russell 1952).

Targeted species sanitation seemed feasible once basic entomological research revealed that the number of truly dangerous mosquito species was very small. Much of the world's heavy burden from mosquito-borne disease was carried by just a few dozen Anopheles and even fewer Aedes species. These basic facts became well-established early in the era of modern mosquito control, and for this reason there were never any global, regional or subregional programmes to eradicate all mosquito species, quite apart from the sheer impracticality of any such undertakings.

\section{A predominant role for synthetic insecticides}

Over the decades, chemical larvicides came to play a substantial role in the control of the anopheline vectors. By the 1930s, with the use of Paris Green as a larvicide, it became possible to eliminate two species of mosquitoes that had spread beyond their regional habitats in sub-Saharan Africa. Anopheles arabiensis

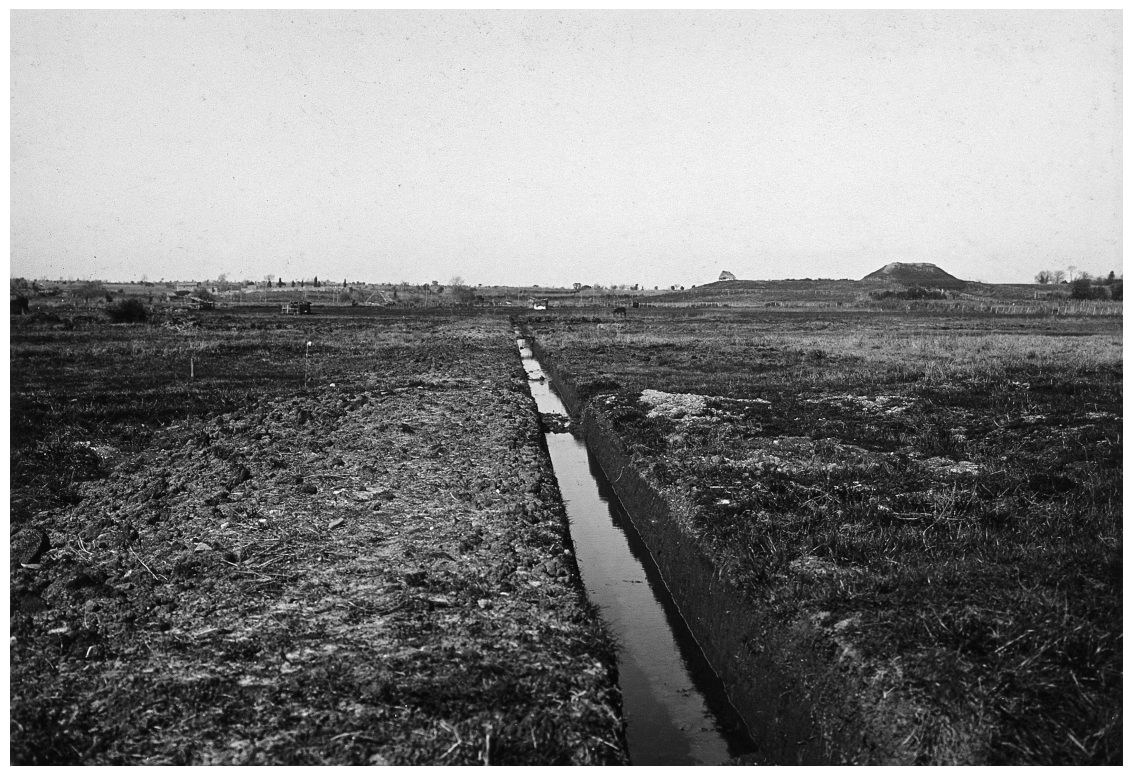

FIGURE 4.2 Nettuno, Italy: a long, narrow drain (to aid mosquito control) in a field. Photograph, ca. 1910-1940. 
was eliminated in northeastern Brazil in the 1930s, and following the discovery of DDT during the Second World War, Anopheles gambiae, which had infiltrated Egypt from the south, was locally eradicated. Neither of these campaigns used drainage or flooding to accomplish their goals.

These successes in South America and North Africa with Paris Green anticipated the experimentation with DDT during the last phases of the Second World War and in the immediate post-war period. The most significant of the early undertakings was the post-war programme to stop malaria transmission on the island of Sardinia, which then shifted to target the species eradication of the island's malaria vector, Anopheles labranchiae. Workers sprayed DDT on breeding sites across the entire island, as well as in the interiors of buildings, as an investigative project to test whether regional eradication of an indigenous mosquito species was possible. The results showed that malaria had largely been eliminated from Sardinia, but not the mosquito. The complete island-wide eradication of Anopheles labranchiae proved unattainable. The few remaining covert breeding sites, along with the inadvertent reintroduction of Anopheles labranchiae to the island, allowed for the re-establishment of scattered malaria infections, although at dramatically reduced levels (Brown 1991, Hall 2010).

In the United States, malaria had all but disappeared by the end of the 1940s. The construction of dams and the treatment of impounded waters, the draining of wetlands, the relocation of populations from low-lying areas, and the ready availability of prophylactic and curative quinine had achieved most of this success, and in the final years of the decade the application of DDT for mosquito control played a small role (Humphreys 2001). In much of Western Europe, there was a comparable reduction in malaria transmission, owing to the draining of wetlands, increases in agricultural production and standards of living, the screening of houses, and the availability of quinine (Bruce-Chwatt and de Zueleta 1980).

Following a post-war period of experimentation with DDT for malaria control, in 1955 the World Health Organization launched a global campaign based principally on indoor residual spraying with synthetic insecticides - principally DDT - to reduce mosquito densities and to interrupt malaria transmission. The malaria specialists considered it a race against the clock: although it was clear from the start that the wide application of DDT would select for resistance in insects and that it was only a matter of time until mosquito resistance emerged, the logic of the programme balanced upon the notion that rolling out the programme rapidly would be the best hope for interrupting disease transmission globally before resistance emerged (Packard 1998). The Global Malaria Eradication Programme (GMEP) racked up impressive victories, greatly reducing the levels of morbidity and mortality in all world regions outside of sub-Saharan Africa and achieving, on some islands such as Taiwan and most of the Caribbean islands, the complete interruption of malaria transmission. Yet by the time the programme ended in 1969, it was clear that in most other regions, continued spraying with DDT and other residual insecticides would not be able to put an end to malaria transmission. Resistance to insecticides 
had indeed emerged in some regions; international donors and national governments were unwilling to bear the ongoing costs of the GMEP; malaria specialists deemed the eradication effort in sub-Saharan Africa to be infeasible, owing to an array of insurmountable obstacles (Webb 2011, 2014); and crucially, the GMEP was in political terms judged a failure because it did not achieve its goal of global malaria eradication (Litsios 1996).

A somewhat different scenario played out with regard to yellow fever. Fred Soper, who had directed the regional eradication of Anopheles arabiensis in Brazil, the successful yellow fever suppression campaign against Aedes aegypti in that country, and the regional eradication of Anopheles gambiae in Egypt, was a dedicated advocate of species sanitation who embraced DDT as a crucial larvicide. Soper became director of the Pan American Health Organization in 1947, launching a programme to eradicate Aedes aegypti from the Western Hemisphere. It enjoyed large successes, but as political wills and economic resources waned in the early 1960s, Aedes aegypti began to fully recolonize and then expand beyond its previous range (Gubler 2004, Stepan 2011, Webb 2016).

\section{DDT, disease control, and environmentalism}

DDT, like the earlier lead- and arsenic-based insecticides, worked against a full range of insects, including those which threatened agriculture (Whorton 1974). In the post-Second World War years, farmers began to use the chemical broadly, and during the 1950s and 1960s, the use of DDT in agriculture spread globally. DDT was effective in sharply increasing crop yields and limiting losses owing to insect infestations. This was immensely important in many regions of the world, including those that were struggling to produce enough food for their burgeoning populations as well as those struggling to overcome the devastation of the world war. Yet the apparent "agricultural miracle" of DDT, even early on, had shown intimations of a dark side. There were warning signs that the profligate use of insecticides in agriculture produced broad, untoward ecological consequences. Biologists and wildlife specialists reported that heavy applications of DDT killed fish, birds and rodents in addition to insects. Initially, these reports had limited impact. It was not until the publication of Rachel Carson's 1962 blockbuster Silent Spring — a book whose title evoked a future world without birdsong - that a general alarm was rung. The book crystallized the issue of how ecological damage stemmed from the profligate use of pesticides. It played a major role in the birth of environmentalism as a political movement.

The early environmental movement produced tangible results. In 1972, under mounting political pressure, the US government banned DDT for agricultural purposes, reserving it exclusively for use in public health emergencies. This was understandably counted as a major victory by the environmental movement. Yet, ironically, DDT was the least toxic of the chlorinated hydrocarbons used as pesticides, and after its agricultural ban, farmers substituted more dangerous organophosphates (Davis 2014). 
The environmental movement also sought more broadly to limit the "destruction" of the environment, and activists advocated for the reversal of earlier land-use transformations, such as the "reclamation" of wetlands through drainage. By the 1980s, the memory of earlier struggles against mosquito-borne diseases had faded. The environmentalists, charged with concerns that human activities were bringing humanity towards a critical tipping point, after which ecological recovery would be increasingly difficult if not impossible, sought to ban synthetic insecticides, including DDT, even for disease control. This put the environmental movement in the Global North on a collision course with public health specialists in the Global South, where malaria was killing one or two million people every year (Murray et al. 2012).

The conflict came to a head in the 1990s, when environmentalists pushing for a universal ban on persistent organic pollutants (POPs) ran up against a consortium of states in the Global South that lobbied for the continued use of DDT and other synthetic insecticides that helped control vector-borne diseases. The result was an accommodation that allowed for ongoing use of DDT and other chemical insecticides in disease control, where needed-in the Global South.

Taking the long view, it is evident that the historical experiences with mosquito-borne disease in the Global North and the Global South underlay the different attitudes towards DDT and other synthetic insecticides. In the Global North, in the last decades of the twentieth century, memories of mosquito-borne disease were distant. In the eighteenth and nineteenth centuries, yellow fever had exacted a significant toll along the Gulf Coast of the United States and had ignited intermittent epidemics along the eastern seaboard. The last outbreak had occurred in 1905 in New Orleans. By the 1940s, malaria in the United States had been defeated. Western Europeans had experienced their last outbreak of yellow fever in the mid-nineteenth century and saw the incidence of malaria drop to near zero in the immediate post-Second World War years. By contrast, mosquito-borne disease in the Global South resurged in the late twentieth century. In the 1980s, malaria deaths increased sharply in tropical Africa, and the annual toll remained high until the second global malaria eradication campaign, launched in the 2000s, cut the number of annual malaria deaths approximately in half through the use of insecticide-treated bed nets, indoor house-spraying with DDT and other residual insecticides, and artemisinin-based medications (Webb 2014). Yellow fever annually took an estimated total of tens of thousands of African lives, until a massive immunization campaign was launched in the 2010s (Garske et al. 2014).

In the twenty-first century, a new mosquito challenge has emerged from the cauldron of climate change. The Asian "tiger mosquito," Aedes albopictus, which successfully breeds in small collections of rainwater, has extended its range around the world by virtue of the global trade in used tyres. It exploits both domestic and non-domestic breeding sites, and it is capable of transmitting the 
same arboviruses (yellow fever, dengue fever, chikungunya and Zika) as Aedes aegypti. Aedes albopictus, however, has a geographical range far more extensive than that of Aedes aegypti. Some specialists fear that the expansion of Aedes albopictus may portend the transmission of dengue fever, chikungunya and Zika in eastern North America, Southern Europe, East Asia and Australia.

In recent years, new tools have become available for mosquito control, including the release of "sterile" or otherwise genetically modified mosquitoes, in order to prevent disease transmission. These new approaches to mosquito control have been controversial. Some observers have raised concerns about the potential for deleterious and unintended biological consequences. The ethical and ecological issues are still under discussion. Some limited releases of genetically modified mosquitoes have been carried out, but the practice has not become widely accepted.

The long history of human-mosquito relations will continue to be fraught. In the past, a few targeted efforts to eliminate mosquito vector species have been successful on a regional basis. There has never been, however, any serious proposal for the regional elimination or global eradication of all mosquito species. Because relatively few mosquito species pose threats to human health, any such proposal for regional elimination or global eradication would be misguided as well as ecologically perilous. For the foreseeable future, efforts to suppress mosquitoborne disease transmission will continue to concentrate on the most dangerous species, and in virtually all regions the goal will remain the reduction of these vector populations rather than their local elimination.

\section{Bibliography}

Bourn, Warren S., and Clarence Cottam. 1950. Some Biological Effects of Ditching Tidewater Marshes. Fish and Wildlife Service, U. S. Department of the Interior, No. 19. Washington, DC: U.S. Government Printing Office.

Bruce-Chwatt, L.J., and J. de Zulueta. 1980. The Rise and Fall of Malaria in Europe. Oxford: Oxford University Press.

Carson, Rachel. 1962. Silent Spring. New York: Houghton Mifflin Company.

Coleman, William. 1987. Yellow Fever in the North. Madison: University of Wisconsin Press.

Crain, Caitlin Mullan, Keryn Bromberg Gedan, and Michele Dionne. 2009. Tidal restrictions and mosquito ditching in New England marshes. In Brian R. Silliman, Edwin D. Grosholz, and Mark D. Bertness (eds.) Human Impacts on Salt Marshes: A Global Perspective. Berkeley: University of California Press, 149-169.

Daiber, Franklin. 1986. Conservation of Tidal Marshes. New York: Van Nostrand Reinhold.

Davis, Frederick Rowe. 2014. Banned: A History of Pesticides and the Science of Toxicology. New Haven: Yale University Press.

Dobson, Mary. 1980. "Marsh Fever"-the geography of Malaria in England. Journal of Historical Geography 6, no. 4: 357-389.

Farley, John. 2003. To Cast Out Disease: A History of the International Health Division of the Rockefeller Foundation (1913-1951). Oxford: Oxford University Press. 
Garske, Tini, Maria D. Van Kerkhove, Sergio Yactayo, Olivier Ronveaux, Rosamund F. Lewis, J. Erin Staples, William Perea, Neil M. Ferguson, and Yellow Fever Expert Committee. 2014. Yellow fever in Africa: Estimating the burden of disease and impact of mass vaccination from outbreak and serological data. PLoS Medicine 11, no. 5: e1001638.

Gubler, Duane J. 2004. The changing epidemiology of yellow fever and Dengue, 1900 to 2003: Full circle? Comparative Immunology, Microbiology and Infectious Diseases 27, no. 5: 319-330.

Hall, Marcus. 2010. Environmental imperialism in Sardinia: Pesticides and politics in the struggle against malaria. In Marco Armiero and Marcus Hall (eds.) Nature and History in Modern Italy. Athens: Ohio University Press, 70-86.

Harrison, Gordon. 1978. Mosquitoes, Malaria and Man: A History of the Hostilities Since 1870. New York: Dutton.

Hatvany, Matthew George. 2003. Marshlands: Four Centuries of Environmental Change on the Shores of the St. Lawrence. Quebec: Presses de l'Université Laval.

Holmes, Oliver Wendell. 1838. Dissertation on intermittent fevers in New England. Boyleston Prize Dissertations for the Years 1836 and 1837. Boston: C.C. Little and J. Brown.

Humphreys, Margaret. 2001. Malaria: Poverty, Race, and Public Health in the United States Baltimore: Johns Hopkins University Press.

Iroko, A. Félix. 1994. Une histoire des hommes et des moustiques en Afrique. Paris: Harmattan.

Litsios, Socrates. 1996. The Tomorrow of Malaria. Karori, NZ: Pacific Press.

McNeill, John R. 2010. Mosquito Empires: Ecology and War in the Greater Caribbean, 16201914. New York: Cambridge University Press.

Murray, Christopher JL, Lisa C. Rosenfeld, Stephen S. Lim, Kathryn G. Andrews, Kyle J. Foreman, Diana Haring, Nancy Fullman, Mohsen Naghavi, Rafael Lozano, and Alan D. Lopez. 2012. Global Malaria Mortality between 1980 and 2010: A systematic analysis. Lancet 379, no. 9814: 413-431.

Packard, Randall M. 1998. "No Other Logical Choice": Global Malaria eradication and the politics of international health in the post-war era. Parassitologia 40: 217-229.

Patterson, Gordon. 1998. The Mosquito Wars: A History of Mosquito Control in Florida. Gainesville, FL: University of Florida Press.

Patterson, Gordon. 2009. The Mosquito Crusades: A History of the American Anti-Mosquito Movement from the Reed Commission to the First Earth Day. New Brunswick: Rutgers University Press.

Ranwell, D.S. 1967. World resources of Spartina townsendii (sensu lato) and economic use of Spartina Marshland. Journal of Applied Ecology 4, no. 1: 239-256.

Russell, Paul F. 1952. The eradication of Malaria. Scientific American 186, no. 6: 22-25.

Seasholes, Nancy S. 2018. Gaining Ground: A History of Landmaking in Boston. Boston: MIT Press.

Sergent, Edmond, and Etienne Sergent. 1947. Histoire d'un marais algérien. Algiers: Institut Pasteur d'Algérie.

Snowden, Frank M. 2006. The Conquest of Malaria: Italy, 1900-1962. New Haven: Yale University Press.

Stepan, Nancy Leys. 2011. Eradication: Ridding the World of Diseases Forever. Ithaca: Cornell University Press.

United States Public Health Service and Tennessee Valley Authority. 1947. Malaria Control on Impounded Water. Washington, DC: U.S. Government Printing Office.

Verhave, Jan Peter. 2011. The Moses of Malaria: Nicolaas H. Swellengrebel (1885-1970), Abroad and at Home. Rotterdam: Erasmus Publishing. 
60 James L.A. Webb, Jr.

Watson, Malcolm. 1921. The Prevention of Malaria in the Federated Malay States: A Record of Twenty Years' Progress. London: John Murray.

Watson, Malcolm. 1953. African Highway: The Battle for Health in Central Africa. London: John Murray.

Webb, Jr., James L.A. 2009. Humanity's Burden: A Global History of Malaria. New York: Cambridge University Press.

Webb, Jr., James L.A. 2011. The first large-scale use of synthetic insecticides for Malaria control in tropical Africa. Journal of the History of Medicine and Allied Sciences 66, no. 3: 347-376.

Webb, Jr., James L.A. 2014. The Long Struggle Against Malaria in Tropical Africa. New York: Cambridge University Press.

Webb, Jr., James L.A. 2016. Aedes aegypti suppression in the Americas: Historical perspectives. Lancet 10044, no. 388: 556-557.

Whorton, James. 1974. Before Silent Spring: Pesticides and Public Health in Pre-DDT America. Princeton: Princeton University Press. 